\title{
Translating Tactical Combat Casualty Care Lessons Learned to the High-Threat Civilian Setting: Tactical Emergency Casualty Care and the Hartford Consensus
}

\author{
David W. Callaway, MD, FACEP \\ From the Carolinas Medical Center, Charlotte, NC.
}

\begin{abstract}
Combat operations necessitate bold thought and afford the opportunity to rapidly evolve and improve trauma care. The development and maturation of Tactical Combat Casualty Care (TCCC) is an important example of a critical process improvement strategy that reduced mortality in high-threat combat-related trauma. The Committee for Tactical Emergency Casualty Care (C-TECC) adapted the lessons of TCCC to the civilian high-threat environment and provided important all-hazards response principles for austere, dynamic, and resource-limited environments. The Hartford Consensus mobilized the resources of the American College of Surgeons to drive public policy regarding a more singular focus: hemorrhage control. The combined efforts of C-TECC and Hartford Consensus have helped redefine the practice of trauma care in high-threat scenarios across the United States.
\end{abstract}

Keywords: TECC, TCCC, Tactical Emergency Casualty Care, Tactical Combat Casualty Care, Hartford Consensus, wilderness medicine, austere medicine

\section{Introduction}

The symbiotic relationship between the military and civilian trauma systems in the United States is responsible for some of the most rapid and consequential advances in the care of critically injured patients. In particular, the translation and evolution of the Tactical Combat Casualty Care (TCCC) guidelines through the Committee for Tactical Emergency Casualty Care (C-TECC) and subsequently the Hartford Consensus (HC) have fundamentally reshaped high-threat trauma response in the United States.

\section{History}

Details surrounding the origin, development, and maturation of the TCCC guidelines are provided elsewhere. ${ }^{1-3}$

Corresponding author: David W. Callaway, MD, FACEP, Director, Operational and Disaster Medicine, Carolinas Medical Center-Main, Charlotte, NC; e-mail: david.callaway@ carolinas.org.

Presented at the Tactical Combat Casualty Care: Transitioning Battlefield Lessons Learned to Other Austere Environments Preconference to the Seventh World Congress of Mountain \& Wilderness Medicine, Telluride, Colorado, July 30-31, 2016.
Between 2001 and 2015, the Committee on Tactical Combat Casualty Care (CoTCCC) helped to drive innovation in combat trauma care and was partially responsible for some of the lowest case fatality rates in recorded military history. ${ }^{4-6}$ Many frontline observations related to resuscitation and surgical intervention were validated at civilian academic centers and quickly applied back on the battlefield in Iraq and Afghanistan. ${ }^{7,8}$ However, the power of TCCC lay in the systematic application of threat-based interventions to reduce potentially preventable mortality in the prehospital environment. Initial efforts (ie, in 2003-2009) to apply the prehospital combat lessons learned to the civilian sector were ad hoc and primarily focused on special weapons and tactics teams. The National Association of Emergency Medical Technicians (NAEMT) and Prehospital Trauma Life Support led initial efforts to formally bring TCCC lessons to the civilian sector. Broad implementation was hindered by local concerns about en bloc application of military protocols to the civilian sector. However, the disturbing increase in active shooter incidents in the United States during this period fueled efforts to speed the appropriate translation of combat lessons learned. 
In 2009, efforts to translate TCCC into the civilian sector accelerated. Nationally, a critical mass was reached; public and private sector entities (eg, NAEMT, the National Tactical Officer Association) that had been creating similar but distinct training, education, and doctrine recognized an unstated requirement to unify efforts, create common language, and codify response principles for high-threat casualty care. The resulting efforts led to the creation of the C-TECC and the HC.

\section{The Committee for Tactical Emergency Casualty Care}

The C-TECC convened in 2010 to coordinate national ad hoc efforts to translate TCCC into civilian practice. The C-TECC is a best-practice development group for the provision of trauma care in high-threat, prehospital environments. Modeled after the CoTCCC, the C-TECC comprises a broad range of interagency operational and academic leaders in the practice of high-threat medicine. ${ }^{9}$ The original Tactical Emergency Casualty Care (TECC) guidelines published in 2011 represented the first broadly accepted set of civilian all-hazards, high-threat trauma care guidelines. ${ }^{9}$ The guidelines were based largely off of the most recent TCCC guidelines with linguistic changes to reflect the civilian operational environment (eg, removal of phrases such as "the best medicine on the battlefield is fire superiority") and minor modifications in recommended procedures. The guidelines provided clear recommendations for integration of operational requirements into trauma care and articulated the importance of threat mitigation, hemorrhage control, and rapid evacuation of casualties. In TECC, care recommendations are modeled after the TCCC phases of care and described in the 3 fluid, threatbased phases of Direct Threat Care, Indirect Threat Care, and Evacuation Care.

The TECC guidelines have evolved over the past 5 years to reflect the unique constraints and characteristics of civilian high-threat response, including care for pediatric patients, lack of body armor, legal requirements, engagement of civilian leadership, education of the public, creation of integrated response models, and even the adaptation of TECC for the operational K9. ${ }^{10,11}$ Critically, the TECC guidelines also reflect that, in the civilian setting, most high-threat missions are inherently rescue missions. Accordingly, the guidelines have always emphasized the importance of casualty access and extraction/evacuation. The TECC guidelines incorporate best-practice and evidence-based guidelines to form a practical set of trauma care principles. ${ }^{12,13} \mathrm{In}$ addition, C-TECC has focused on driving research to discern the distinctions in etiologies of mortality in combat versus civilian high-threat incidents. ${ }^{14}$

Domestic first responder agencies quickly implemented TECC training programs and, particularly within the law enforcement community, a paradigm shift emerged. Law enforcement tactics, techniques, and procedures in response to active shooter incidents began to reflect the twofold response paradigm of "Stop the killing; stop the dying." TECC became the critical link between the 2 operational requirements with multiple case reports of law enforcement interventions, in particular tourniquets, saving lives. ${ }^{15,16}$ At the national level, a variety of governmental and professional organizations endorsed TECC or incorporated the guidelines into their recommended trauma response to high-threat civilian prehospital trauma care. ${ }^{17-20}$ As a result of this extensive local, regional, and national support, over 150000 law enforcement officers, paramedics, firefighters, and physicians have been trained in TECC since 2011 (C-TECC Board of Directors, unpublished data, April 2016). The importance of this full-spectrum integration is illustrated in the TECC Chain of Survival concept (Figure 1). In 2016, at the joint Special Operations Medical Association-Department of Homeland Security Office of Health Affairs Tactical EMS (TEMS) Summit, participants from over 20 national organizations voted to include TECC as the sole trauma care domain for the National TEMS Initiative and Council Core Competency Framework. $^{21}$

\section{Hartford Consensus}

In 2013, motivated by the devastating 2012 Sandy Hook elementary school massacre, a group of national subject matter experts convened to develop strategies to increase survivability in mass casualty shootings. Several of these leaders were longtime CoTCCC members and were intimately involved in the formation of C-TECC 2 years earlier. The meeting resulted in the publication of a concept document, entitled the Hartford Consensus (HC), that laid out a strategic framework for engaging the American College of Surgeons Committee on Trauma and leveraging their significant educational, public relations, and policy resources to effect change on a national level.

The initial HC paper echoed the original TECC guidelines, emphasized hemorrhage control, restated the importance of integrated first responder operations, and was most notable for the creation of the useful briefing and training mnemonic THREAT ${ }^{22,23}$ :

- Threat suppression

- Hemorrhage control 


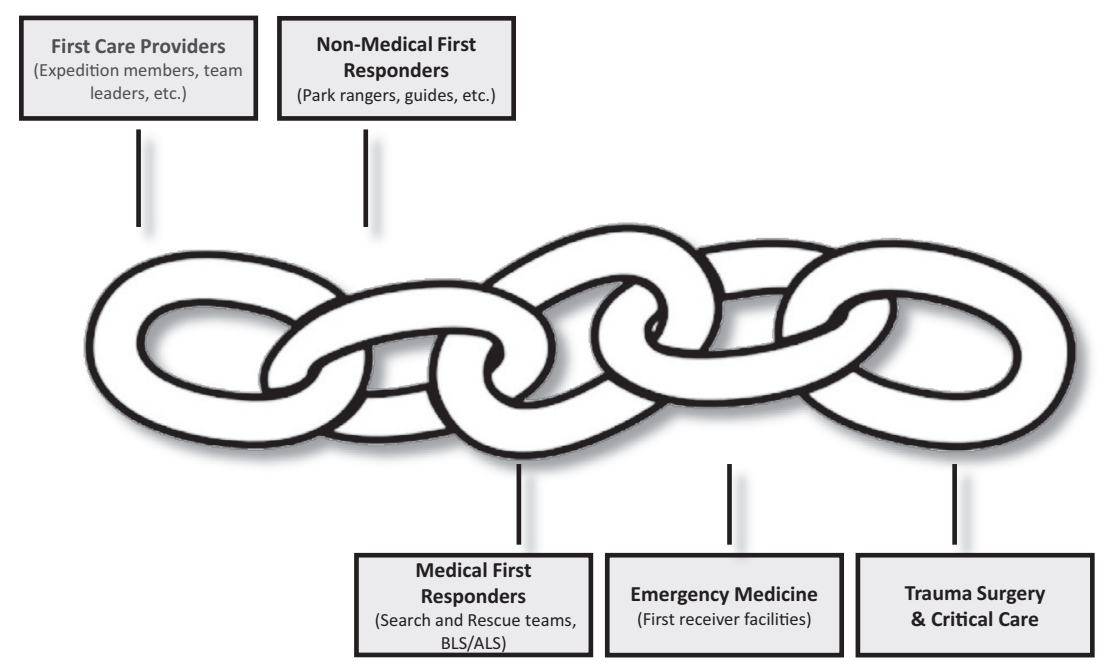

Figure 1. Tactical Emergency Casualty Care (TECC) Chain of Survival. The TECC Chain of Survival highlights the importance of common language principles that can be applied in a tiered manner across an entire community. This model combines attributes of the Ranger First Responder program and the American Heart Association Chain of Survival for Cardiac Arrest.

- Rapid Extrication to safety

- Assessment by medical providers

- Transport to definitive care

Between 2013 and 2016, the HC met 4 times (HC I-IV) and published complementary documents designed to reduce potentially preventable death in active shooter incidents, primarily through a focus on hemorrhage control (Figure 2). The HC group drew heavily from military experience and successful ongoing civilian efforts. ${ }^{24}$ The initial work of the $\mathrm{HC}$ led the America College of Surgeons to establish the Joint Committee to Create a National Policy to Enhance Survivability from Intentional Mass-Casualty and Active Shooter Events. ${ }^{25}$ Subsequent HC work continues to build a comprehensive public awareness and education campaign engaging a wide variety of professional organizations and governmental entities, including the White House.

The HC has been very effective at creating educational content (eg, National Association of Emergency Medical Technician Bleeding Control course) and driving public policy discourse at the highest levels. Compared with CTECC, the HC group reflects a complementary but distinct approach to improving community resilience and translating military lessons learned to the civilian high-threat environment. The TECC guidelines provide broad, threat-based principles of care to address all potentially preventable injuries. The HC, HC II-IV in particular, focuses primarily on reducing mortality via hemorrhage control.

The combined efforts of C-TECC and the HC have resulted in coalitions of nearly every major professional organization, relevant government agency, and private sector partner in the nation, all working toward the reduction of mortality and morbidity in active violent and mass casualty incidents. These laudable efforts have resulted in a major shift in the provision of trauma care in civilian high-threat environments.

\begin{tabular}{|c|c|c|c|}
\hline & Date & Mission Statement & Deliverable \\
\hline $\mathrm{HC} \mathrm{I}$ & April 2, 2013 & $\begin{array}{l}\text { Promote local, state, and } \\
\text { national policies to } \\
\text { improve survival in } \\
\text { active shooter incidents } \\
\text { (ASI). }\end{array}$ & $\begin{array}{l}\text { THREAT: } \\
\text { - Threat suppression } \\
\text { - Hemorrhage control } \\
\text { - Rapid Extrication to safety } \\
\text { - Assessment by medical } \\
\text { providers } \\
\text { - Transport to definitive care }\end{array}$ \\
\hline $\mathrm{HC}$ II & July 11, 2013 & $\begin{array}{l}\text { Preventable death after } \\
\text { an ASI should be } \\
\text { eliminated through the } \\
\text { use of a seamless } \\
\text { integrated response } \\
\text { system (focused on } \\
\text { hemorrhage control). }\end{array}$ & $\begin{array}{l}\text { Continuum of care } \\
\text { recommendations. }\end{array}$ \\
\hline HC III & April 14, 2015 & $\begin{array}{l}\text { Opportunities exist to } \\
\text { improve the control of } \\
\text { external hemorrhage in } \\
\text { the civilian sector. }\end{array}$ & $\begin{array}{l}\text { Implementation of } \\
\text { hemorrhage control strategies } \\
\text { (Stop the Bleed Campaign). } \\
\text { Delineation of three levels of } \\
\text { responders: Immediate } \\
\text { responders, professional first } \\
\text { responders, trauma } \\
\text { professionals. }\end{array}$ \\
\hline HC IV & January 7, 2016 & $\begin{array}{l}\text { Call for increased } \\
\text { national resilience. }\end{array}$ & $\begin{array}{l}\text { Educational strategies for } \\
\text { immediate responders. } \\
\text { - Renewed call for focused } \\
\text { trauma registry and near miss } \\
\text { database. }\end{array}$ \\
\hline
\end{tabular}

Figure 2. The Hartford Consensus (HC) Documents: HC I-IV describe the group's approach to reducing potentially preventable death in active shooter incidents. 


\section{Implications for Other Austere Environments}

Medicine in austere environments centers around the ability to provide critical emergency care in remote, resource-limited settings. Threat-based interventions are a key component of successful medical management. However, as with the civilian high-threat environment, combat lessons learned cannot be applied en bloc to the austere wilderness environment. The key concepts from military and civilian operational medicine that apply in the wilderness are situational awareness, damage control resuscitation, trauma care as a critical individual skill, and proper mission/trip planning.

\section{DAMAGE CONTROL RESUSCITATION}

Damage control resuscitation (DCR) refers to a structured process initiated at point of injury and continued through operative intervention. The key tenets of DCR include early mechanical hemorrhage control, permissive hypotension, limited crystalloid resuscitation, hypothermia prevention, acidosis prevention, and early utilization of balanced blood products. (Note: some authors use the term "hemostatic resuscitation" to include limited crystalloid use, balanced blood product administration, and use of adjuncts such as tranexamic acid.) The DCR process evolved in combat support hospitals and is now widely implemented, and being validated, in civilian trauma centers across North America. ${ }^{26,27}$ Both TCCC and TECC guidelines are structured around providing effective DCR in high-threat environments. ${ }^{28,29}$ The HC efforts have focused on aggressive hemorrhage control as the key component of DCR.

In the wilderness setting, where evacuation times are frequently prolonged and environmental factors make hypothermia a clear risk, many of the principles of DCR are critical. Early extremity hemorrhage control remains critical. Tourniquets still have an important role in initial hemorrhage control, especially during the initial hectic moments after injury. Tourniquet application times of less than 2 hours remain a relatively safe standard..$^{30,31}$ Although this time may be extended in cold environments, no quality data exist to provide sound medical guidance. $^{31,32}$ Accordingly, providers must take into account the entire trip risk profile when making hemorrhage control decisions (eg, duration of evacuation, terrain, potential for additional injuries, effect of control method on patient mobility, etc.). Providers must be diligent in their wound reassessments and, if possible, transition the tourniquet to a pressure dressing as soon as possible if evacuation time is expected to be greater than several hours. Hemostatic dressings may offer an additional advantage over plain gauze for compressible hemorrhage. ${ }^{33-37}$ The key to successful hemorrhage control with existing hemostatic dressings is proper wound packing and application of direct pressure.

Limited crystalloid resuscitation/hypotensive resuscitation and hypothermia prevention are both medical and logistical considerations in wilderness medicine. Permissive hypotension emerged as a resuscitation strategy in the 1990s and was applied aggressively on the battlefields of Iraq and Afghanistan. It remains a key component of DCR in trauma patients without head injuries. (Note: in patients with significant traumatic brain injury, efforts should be made to maintain a systolic blood pressure $\geq 100 \mathrm{~mm} \mathrm{Hg}$ and oxygen saturation of $\geq 95 \% .^{38,39}$ ) The "safe" duration of permissive hypotension is unknown. In all of the studies on hypotensive resuscitation evacuation times were limited, and scant data exist on this resuscitation strategy in prolonged field care/preoperative settings. ${ }^{40-42}$ Limiting crystalloid use in the wilderness may have the added benefit of mitigating iatrogenic hypothermia. Hypothermia affects multiple aspects of the coagulation pathway and is independently correlated with increased mortality from hemorrhage in trauma. ${ }^{42}$

\section{TRAUMA CARE AS AN INDIVIDUAL SKILL}

In remote wilderness environments, the ability to provide basic trauma stabilization should be considered a mission-essential skill set for all team members. Recent military studies suggest that $24 \%$ of US military deaths during recent conflicts were potentially survivable (PS). ${ }^{43}$ However, the rate of PS deaths was found to be approximately $15 \%$ for US Special Operations Forces deaths between 2001 and 2004 and only 3\% for the 75th Ranger Regiment from 2001-2010. The Ranger First Responder program, based upon TCCC principles and predicated on the concept that trauma care is a fundamental soldier skill, was a key component for achieving this significant reduction in combat mortality. ${ }^{44}$ The TECC guidelines endorse the concept of "trauma care as an individual skill" and provide a tiered set of recommendations based on provider skill level. ${ }^{8,45}$ Recently, the HC IV has articulated a parallel call to action regarding training all immediate responders in hemorrhage control. ${ }^{46}$ Similar to the small team operations in combat, all individuals venturing into the wilderness should possess relevant threat-based trauma training; teams cannot rely on a designated medic or external medical assistance when in the backcountry.

\section{MISSION/TRIP PLANNING}

Trauma care in the austere environment is all about logistics; team size affects what equipment is carried 
and how it is spread loaded; team composition and trip goals affect potential injury patterns; and terrain and weather affect injury threat and evacuation modalities. The TCCC guidelines offer good insight into vetted and recommended equipment. And, TECC offers a helpful threat-based care framework to guide planning, team training and trip execution. However, TECC has caveats based on timing. For example, tourniquets should ideally only be left in place for two hours, the safe duration of hypotensive resuscitation is unknown, and the level one data for provision of DCR principles on pediatric patients is very limited. Any team leader or medic should augment their TECC by knowledge of Prolonged Field Care (PFC) or other austere medicine training. ${ }^{47}$

\section{Conclusions}

The past 15 years of combat have brought major advances in the care of the critically ill trauma patient. The cost economically and in human life was not insignificant. It is incumbent on military and civilian trauma leaders to ensure that the gains of the last decade and a half are not only not lost, but continue to spur innovation and advancement in the care of the injured patient. The CoTCCC set a new standard regarding the process for advancing military trauma care. The success of C-TECC reflects a grassroots movement from the tactical and operational level that grew to shape national policy. The history of C-TECC mirrors the inception, development, and maturation of the CoTCCC from renegade frontline operational providers to shapers of public policy. The C-TECC and the HC are building upon that tradition to provide an appropriate translation of relevant military lessons learned to the civilian sector and to drive the public policy discourse toward creation of new national standards in high-threat trauma response. Lessons learned from the civilian high-threat community and from the translation of combat lessons learned should be examined critically and applied in a sensible manner to other austere environments.

Financial/Material Support: None.

Disclosures: None.

\section{References}

1. Llewellyn $\mathrm{CH}$. The symbiotic relationship between operational military medicine, tactical medicine, and wilderness medicine: a view through a personal lens. Wilderness Environ Med. 2017;28(suppl):S6-S11.

2. Butler FK. Tactical combat casualty care: beginnings. Wilderness Environ Med. 2017;28(suppl):S12-S17.
3. Giebner SD. The transition to the committee on tactical combat casualty care. Wilderness Environ Med. 2017;28 (suppl):S18-S24.

4. Eastridge BJ, Costanzo G, Jenkins D, et al. Impact of joint theater trauma system initiatives on battlefield injury outcomes. Am J Surg. 2009;198:852-857.

5. Kelly JF, Ritenour AE, McLaughlin DF, et al. Injury severity and causes of death from Operation Iraqi Freedom and Operation Enduring Freedom: 2003-2004 versus 2006. J Trauma. 2008;64(suppl 2):S21-S26.

6. Butler FK, Blackbourne LH. Battlefield trauma care then and now: a decade of tactical combat casualty care. J Trauma Acute Care Surg. 2012;73:S395-S402.

7. Holcomb JB, Tilley BC, Baraniuk S, et al. Transfusion of plasma, platelets, and red blood cells in a $1: 1: 1$ vs a $1: 1: 2$ ratio and mortality in patients with severe trauma: the PROPPR randomized clinical trial. JAMA. 2015;313:471-482.

8. Holcomb JB, del Junco DJ, Fox EE, et al. The Prospective, Observational, Multicenter, Major Trauma Transfusion (PROMMTT) Study: comparative effectiveness of a time-varying treatment with competing risks. JAMA Surg. 2013;148:127-136.

9. Callaway DW, Smith ER, Cain J, et al. Tactical emergency casualty care (TECC): guidelines for the provision of prehospital trauma care in high threat environments. J Spec Oper Med. 2011;11:104-122.

10. Bobko J, Lai TT, Smith ER, Shapiro GL, Baldridge RT, Callaway DW. Tactical emergency casualty care? pediatric appendix: novel guidelines for the care of the pediatric casualty in the high-threat, prehospital environment. J Spec Oper Med. 2013;13:94-107.

11. Palmer LE, Maricle R, Brenner JA. The operational canine and K9 tactical emergency casualty care initiative. J Spec Oper Med. 2015;15:32-38.

12. Bulger E, Snyder D, Schoelles K, et al. An evidencebased prehospital guideline for external hemorrhage control: American College of Surgeons Committee on Trauma. Prehosp Emerg Care. 2014;18:163-173.

13. American College of Emergency Physicians Policy Statement on Out-of-Hospital Severe Hemorrhage Control, October 2014. Available at: https://www.acep.org/physi cian-resources/policies/policy-statements/ems/out-of-hospi tal-severe-hemorrhage-control/. Accessed August 14, 2016.

14. Smith ER, Shapiro G, Sarani B. The profile of wounding in civilian public mass shooting fatalities. J Trauma Acute Care Surg. 2016;81:86-92.

15. Callaway DW, Robertson J, Sztajnkrycer MD. Law enforcement-applied tourniquets: a case series of lifesaving interventions. Prehosp Emerg Care. 2015;19: 320-327.

16. Robertson J, McCahill P, Riddle A, Callaway D. Another civilian life saved by law enforcement-applied tourniquets. J Spec Oper Med. 2014;14:7-11.

17. Federal Emergency Management Agency. Active Shooter and Mass Casualty Incidents, September 2013. Available at: https://www.usfa.fema.gov/downloads/pdf/publications/ active_shooter_guide.pdf. Accessed June 1, 2016. 
18. Gerold K. National Tactical Officers Association TEMS Position Statement. Available at: https://ntoa.org/sections/ tems/tems-position-statement/. Accessed April 14, 2016.

19. Office of Health Affairs, Department of Homeland Security. First Responder Guide for Improving Survivability in Improvised Explosive Device and/or Active Shooter Incidents Washington, DC: DHS; June 2015.

20. Law Enforcement and First Response Tactical Casualty Care. Available at: http://www.naemt.org/education/LEFRTCC/LEFRTCC.aspx. Accessed June 1, 2016.

21. Pennardt A, Kamin R, Llewellyn C, Shapiro G, Carmona PA, Schwartz RB. Integration of Tactical Emergency Casualty Care (TECC) into the National Tactical Emergency Medical Services (TEMS) competency domains. J Spec Oper Med. 2016;16:62-66.

22. Jacobs LM, McSwain NE Jr, Rotondo MF, et al. Improving survival from active shooter events: the Hartford Consensus. J Trauma Acute Care Surg. 2013;74:1399-1400.

23. Jacobs LM, Wade D, McSwain NE, et al. Hartford Consensus: a call to action for THREAT, a medical disaster preparedness concept. J Am Coll Surg. 2014;218:467-475.

24. Holcomb J, Butler F, Rhee P. Hemorrhage control devices: tourniquets and hemostatic dressings. J Spec Oper Med. 2015;15:153-156.

25. Jacobs LM. Joint Committee to Create a National Policy to Enhance Survivability from Intentional Mass-Casualty and Active Shooter Events. The Hartford Consensus III: implementation of bleeding control: if you see something do something. Bull Am Coll Surg. 2015;100(suppl 1): 40-46.

26. Shrestha B, Holcomb JB, Camp EA, et al. Damagecontrol resuscitation increases successful nonoperative management rates and survival after severe blunt liver injury. J Trauma Acute Care Surg. 2015;78:336-341.

27. Cotton BA, Reddy N, Hatch QM, et al. Damage control resuscitation is associated with a reduction in resuscitation volumes and improvement in survival in 390 damage control laparotomy patients. Ann Surg. 2011;254:598-605.

28. Butler FK, Holcomb JB, Schreiber MA, et al. Fluid resuscitation for hemorrhagic shock in Tactical Combat Casualty Care: TCCC Guidelines Change 14-01-2 June 2014. J Spec Oper Med. 2014;14:13-38.

29. Smith R, Callaway DW. Tactical emergency casualty care. The need for \& evolution of civilian high threat medical guidelines. JEMS. 2014(suppl):10-15.

30. Richey SL. Tourniquets for the control of traumatic hemorrhage: a review of the literature. World J Emerg Surg. 2007;2:28.

31. Fitzgibbons PG, Digiovanni C, Hares S, Akelman E. Safe tourniquet use: a review of the evidence. J Am Acad Orthop Surg. 2012;20:310-319.

32. Kragh JF Jr, O'Neill ML, Walters TJ, et al. Minor morbidity with emergency tourniquet use to stop bleeding in severe limb trauma: research, history, and reconciling advocates and abolitionists. Mil Med. 2011;176:817-823.

33. Garcia-Blanco J, Gegel B, Burgert J, Johnson S, Johnson D. The effects of movement on hemorrhage when QuikClot ${ }^{\mathbb{R}}$
Combat Gauze ${ }^{\mathrm{TM}}$ is used in a hypothermic hemodiluted porcine model. J Spec Oper Med. 2015;15:57-60.

34. Johnson D, Bates S, Nukalo S, et al. The effects of QuikClot Combat Gauze on hemorrhage control in the presence of hemodilution and hypothermia. Ann Med Surg (Lond). 2014;26(3):21-25.

35. Te Grotenhuis R, van Grunsven PM, Heutz WM, Tan EC. Prehospital use of hemostatic dressings in emergency medical services in the Netherlands: a prospective study of 66 cases. Injury. 2016;47:1007-1011.

36. Bennett BL, Littlejohn L. Review of new topical hemostatic dressings for combat casualty care. Mil Med. 2014;179:497-514.

37. Bennett BL, Littlejohn LF, Kheirabadi BS, et al. Management of external hemorrhage in Tactical Combat Casualty Care: chitosan-based hemostatic gauze dressings-TCCC Guidelines-Change 13-05. J Spec Oper Med. 2014;14:4057.

38. American College of Surgeons, Committee on Trauma. ACS TQIP Best Practices in the Management of Traumatic Brain Injury. Available at: https://www.facs.org/ /media/ files/quality \%20 programs/trauma/tqip/traumatic\%20brain \%20injury\%20guidelines.ashx. Accessed August 16, 2016.

39. Dretzke J, Sandercock J, Bayliss S, Burls A. Clinical effectiveness and cost-effectiveness of prehospital intravenous fluids in trauma patients. Health Technol Assess. 2004;8(iii):1-103.

40. Dutton RP, Mackenzie CF, Scalea TM. Hypotensive resuscitation during active hemorrhage: impact on inhospital mortality. J Trauma. 2002;52:1141-1146.

41. Martin RR, Bickell WH, Pepe PE, Burch JM, Mattox KL. Prospective evaluation of preoperative fluid resuscitation in hypotensive patients with penetrating truncal injury: a preliminary report. J Trauma. 1992;33:354-361. discussion 361-362.

42. Klauke N, Gräff I, Fleischer A, et al. Effects of prehospital hypothermia on transfusion requirements and outcomes: a retrospective observatory trial. BMJ Open. 2016;6:e009913.

43. Eastridge BJ, Mabry RL, Seguin P, et al. Death on the battlefield (2001-2011): implications for the future of combat casualty care. J Trauma Acute Care Surg. 2012;73(6 suppl 5):S431-S437.

44. Kotwal RS, Montgomery HR, Kotwal BM, et al. Eliminating preventable death on the battlefield. Arch Surg. 2011;146:1350-1358.

45. Fisher AD, Callaway DW, Robertson JN, Hardwick SA, Bobko JP, Kotwal RS. The Ranger First Responder Program and Tactical Emergency Casualty Care implementation: a whole-community approach to reducing mortality from active violent incidents. J Spec Oper Med. 2015; 15:46-53.

46. Jacobs LM. Joint Committee to Create a National Policy to Enhance Survivability from Intentional Mass Casualty and Active Shooter Events. The Hartford Consensus IV: a call for increased national resilience. Bull Am Coll Surg. 2016;101:17-24.

47. Keenan S. Prolonged Field Care Working Group update. J Spec Oper Med 2016;16:105-106. 